\title{
Modelling of strong motion generation areas for a great earthquake in central seismic gap region of Himalayas using the modified semi-empirical approach
}

\author{
Sandeep ${ }^{1}$, A Joshi ${ }^{2}$, S K Sah ${ }^{1}$, Parveen $\mathrm{Kumar}^{3, *}$, Sohan $\mathrm{Lal}^{2}$ and $\mathrm{Kamal}^{2}$ \\ ${ }^{1}$ Department of Geophysics, Banaras Hindu University, Varanasi, India. \\ ${ }^{2}$ Department of Earth Sciences, Indian Institute of Technology Roorkee, Roorkee, India. \\ ${ }^{3}$ Wadia Institute of Himalayan Geology, Dehradun, India. \\ *Corresponding author. e-mail: sainiparveen.saini@gmail.com
}

MS received 1 February 2018; revised 15 September 2018; accepted 19 September 2018; published online 2 April 2019

Over the past decades, strong motion generation areas (SMGAs) have received significant attention in the modelling of high-frequency records. Herein, we propose the source model for a scenario earthquake $\left(M_{\mathrm{w}}\right.$ 8.5) in the central seismic gap region of Himalayas. On the rupture plane, three SMGAs have been identified. Further, SMGA parameters are evaluated using available empirical relations. The spatiotemporal distribution of aftershocks is utilised to locate these SMGAs on the rupture plane. Further, the modified semi-empirical technique (MSET) is used to simulate the strong motion records. It has been observed that the study area can expect peak ground acceleration of $>100 \mathrm{~cm} / \mathrm{s}^{2}$ and its distribution is mainly affected by the location of nucleation point in the rupture plane. Furthermore, the estimated peak ground acceleration (PGA) values are comparable with the earlier studies in the region. This confirms the robustness of generated rupture model with three SMGAs and the reliability of MSET to simulate high-frequency records.

Keywords. Central seismic gap; semi-empirical; SMGA; 1991 Uttarkashi earthquake.

\section{Introduction}

Fifty million years ago, the collision between the Eurasian and Indian plates resulted into the rise of Himalayas. Over the past two centuries, four earthquakes of magnitude above 8 have occurred in the Himalayan belt and no great earthquake had occurred since 1950 (Bilham 1995; Khattri 1999). However, the major portion of the converging plate boundary remains unruptured. Therefore, Khattri and Tyagi (1983) and Khattri (1987) have described three seismic gaps along the Himalayan belt based on the seismicity pattern of the region. The central seismic gap (CSG) is the longest one that stretches between the epicentral locations of the great 1905 Kangra earthquake and 1934 Bihar earthquake mainshocks (figure 1). They suggested that the CSG can be a possible zone for two future great earthquakes $\left(M_{\mathrm{w}} \geq 8\right)$. Meanwhile, Bilham et al. (2001) also predicted a future earthquake $\left(M_{\mathrm{w}} \geq 8\right)$ based on the strain accumulation study. Recently, Srivastava et al. (2015) demonstrated two different seismic gaps in the Himalayan region by systematically studying the data from different sources. In seismic gap category 1, earthquake of magnitude $\geq 8$ has occurred and could reoccur. In seismic gap category 2 , earthquakes with magnitude $<8$ have occurred or likely to occur, 


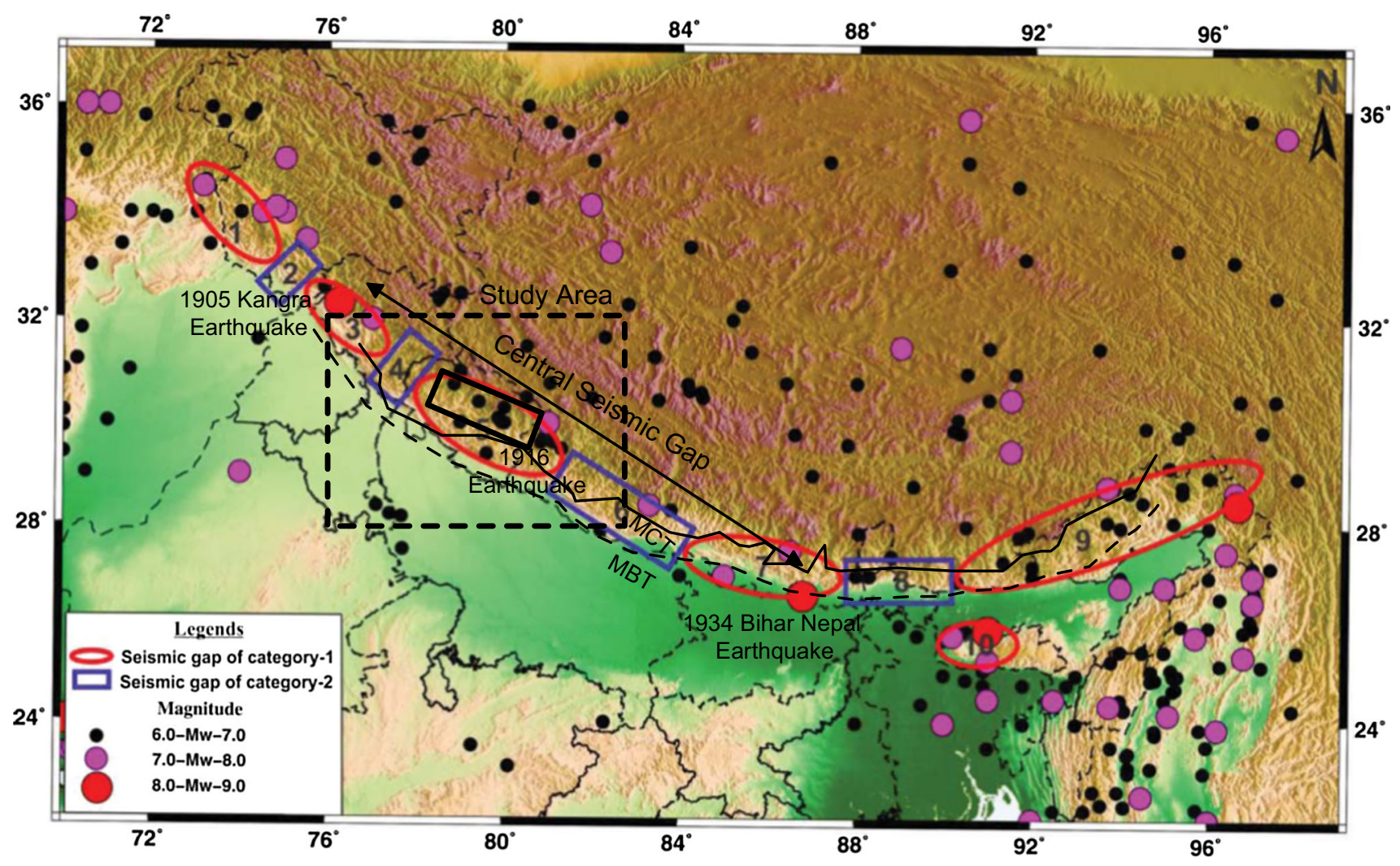

Figure 1. Stretch between the great 1905 Kangra earthquake and the 1934 Bihar earthquake shows the identified CSG (Khattri 1987). Dotted rectangle shows the study area; solid rectangle represents the possible location of the rupture plane for $M_{\mathrm{w}} 8.5$ magnitude earthquake in CSG (Yu et al. 1995). Seismicity shown in figure is for the time periods of 1505-2011 (map modified after Kayal 2014; Srivastava et al. 2015).

as shown in figure 1 . The major portion of the Himalayas in the Uttarakhand region lies in category 1 seismic gap and prone to an earthquake of magnitude $>8.0$ (figure 1 ). This region comprises many large hydroelectric power plants and hence requires detailed examination of the seismic hazard. For this purpose, the estimation of earthquake engineering parameters such as peak ground motion values using simulated records is desirable. Using the specific source patch models, strong motion records can be successfully modelled. These patches with high slip rate along with the rupture plane are termed as strong motion generation areas (SMGAs) (Miyake et al. 2003). Many research groups such as Miyake et al. (1999, 2001, 2003), Kamae and Kawabe (2004), Miyahara and Sasatani (2004), Suzuki and Iwata (2007), Takiguchi et al. (2011), Kurahashi and Irikura (2011) and Asano and Iwata (2012) have successfully simulated strong motion records using empirical Green's function technique and rupture model incorporating SMGAs. However, the above approach is quite reliable but the requirement of aftershock records is a primary obstacle.
In this context, the semi-empirical technique (Midorikawa 1993) has been developed as a powerful tool that effectively simulates the strong motion records. In this technique, aftershock records have been successfully replaced with the envelope function of time records. Therefore, this paper demonstrates the application of modified semi-empirical technique (MSET) to model SMGAs in the rupture plane of great earthquake in the CSG region.

\section{Geology and seismotectonics}

The Kumaon and Garhwal regions of Himalayas are the two most putative sites of future devastating earthquakes. The high seismicity and active thrust system demonstrated that the Main Boundary Thrust (MBT) and Main Central Thrust (MCT) are the most significant tectonic features of the above regions. High-grade metamorphic crystalline rocks occurred in the north of MCT while the brittle fracture characterised MBT (figure 2). However, several research groups have contradicted the above view on seismotectonics of Himalayas. 

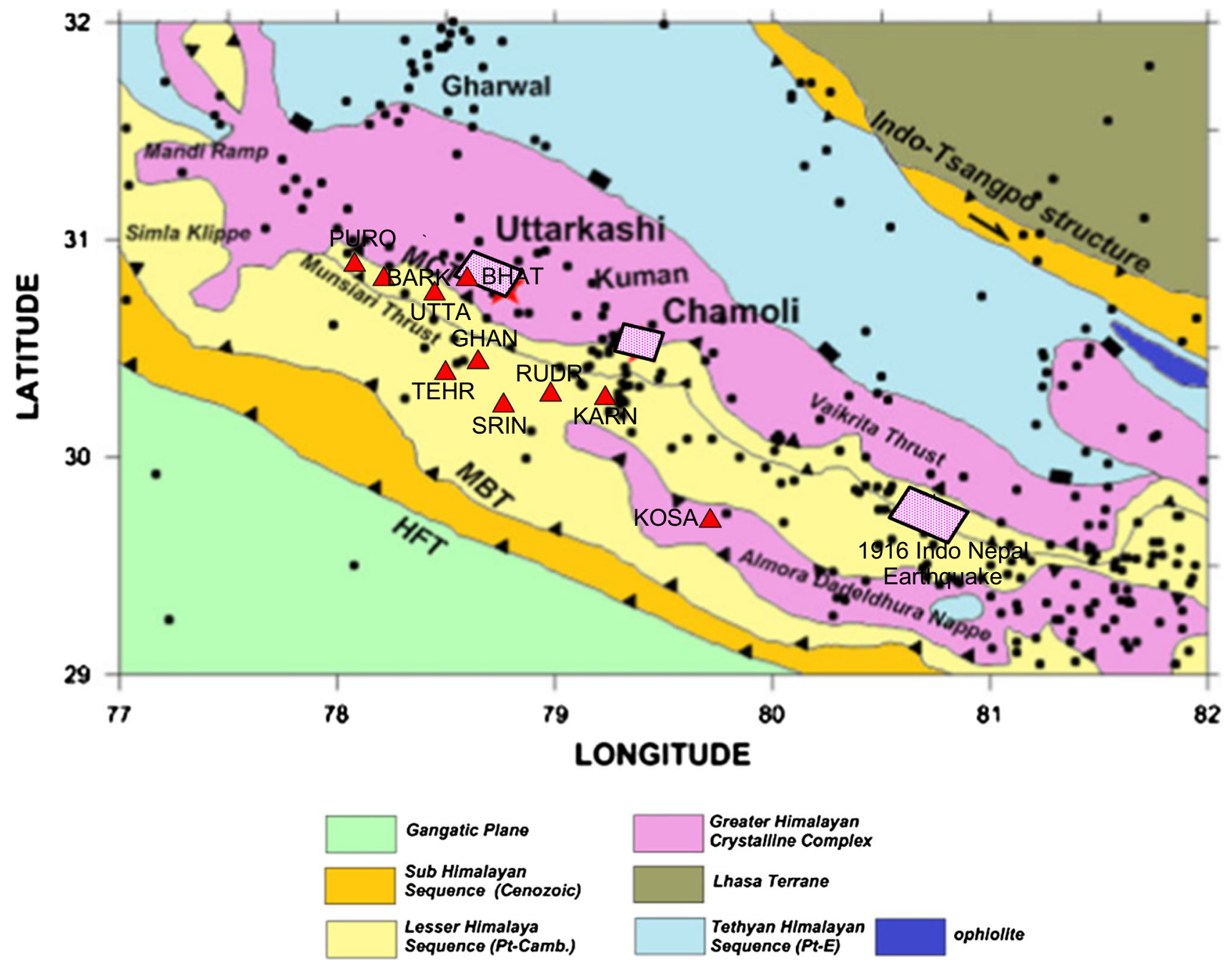

Figure 2. Geological and seismicity map of the Kumaon and Garhwal Himalaya along with 10 recording stations (red triangle). Three rectangles are the rupture planes (Joshi 2004; Wells and Coppersmith 1994) of the 1916 Indo Nepal $\left(M_{\mathrm{w}}\right.$ 7.0), 1991 Uttarkashi $\left(M_{\mathrm{w}} 6.8\right)$ and 1999 Chamoli $\left(M_{\mathrm{w}} 6.5\right)$ earthquakes in this region. Black dots represent the epicentre of the earthquakes of $M_{\mathrm{w}}>4$. MCT, Main Central Thrust; MBT, Main Boundary Thrust; HFT, Himalayan Frontal Thrust (map modified after Chopra et al. 2012).

For instance, Ni and Barazangi (1984) proposed that the MCT is less active than the MBT and suggested other adjacent thrusts in the Himalayan arc. On the other hand, Seeber et al. (1981) postulated that seismicity is mostly concentrated between the MBT and MCT and the earthquakes of intermediate magnitude are usually occurred on a steeply dipping basement thrust of MCT. According to the IMD catalogue (2012), 11 earthquakes of magnitude between 6 and 7 were reported in the western part of CSG. This comprises 1916 Indo Nepal $\left(M_{\mathrm{w}} 7.0\right)$, the 1991 Uttarkashi $\left(M_{\mathrm{w}} 6.8\right)$ and the 1999 Chamoli $\left(M_{\mathrm{w}} 6.5\right)$ earthquakes. The rupture planes of aforementioned earthquakes have been shown in figure 2.

On the basis of intensity sustained from past earthquakes, the IS:1893 (2002) Bureau of Indian standard (BIS) has subdivided India into four seismic zones - II, III, IV and V. Seismic zones II and $\mathrm{V}$ are the lowest and highest earthquake prone areas, respectively. The Uttarakhand state falls in between the seismic zones IV and V, and hence, it is referred as high earthquake prone area. Moreover, Global Seismic Hazard Assessment Program (GSHAP) data revealed that the state of Uttarakhand falls in a region of high to very-high seismic hazard. However, Joshi and Mohan (2010) reported the assessment of seismic hazards for moderate earthquakes in Himalayas using the deterministic approach. Bhatia et al. (1999) identified two source zones of M7.5 earthquakes in Himalayas. Furthermore, Nath et al. (2008) postulated that the ground motion of a scenario earthquake $\left(M_{\mathrm{w}} 8.5\right)$ has $10 \%$ exceedance probability for the next 50 yrs. Over 
the past decades, this region has also witnessed enormous seismicity (figure 2).

\section{Methodology}

In this paper, the MSET pioneered by Midorikawa (1993) has been used to simulate strong motion records (Sandeep et al. 2014b). Over the past decades, many researchers have successfully used the above-mentioned technique in simulating strong motions (e.g., Joshi and Patel 1997; Kumar et al. 1997; Joshi et al. 1999, 2001, 2012a, b, 2014, 2015; Joshi 2001, 2004; Joshi and Midorikawa 2004; Sandeep et al. 2014a, b, 2015, Sandeep et al. $2017 \mathrm{a}, \mathrm{b}, \mathrm{c})$. In the MSET technique, the rupture plane of the target earthquake is subdivided into equal area grids and called as subfaults. The division is governed by self-similarity laws, suggested by Aki (1967) and later modified by Kanamori and Anderson (1975). After several years, Boore (1983) described the acceleration spectra $A(f, R)$ as follows:

$$
A(f, R)=C S(f) D(f) F(f, R),
$$

where $C$ is a constant scaling factor, $S(f)$ and $D(f)$ are the source acceleration spectrum (Brune 1970) and attenuation of high frequencies, respectively, and $F(f, R)$ represents the attenuation factor (Boore 1983).

The present technique entails the multiplication of theoretical filters proposed by Boore (1983) with band limited spectrum and finite duration white Gaussian noise. The above-mentioned outcome obtains the acceleration spectra for each subfault, which correspond to acceleration records in the time domain. Due to the difference between the slip duration of the target and small earthquake (subfaults), these acceleration records need to be corrected and thus combining the earlier simulated records $a_{i j}(t)$ with correction function $F(t)$.

The corrected acceleration records $A_{i j}(t)$ are generated by combining the earlier simulated records $a_{i j}(t)$ with the correction function $F(t)$ (Irikura and Kamae 1994; Irikura et al. 1997) as follows:

$$
A_{i j}(t)=F(t) \times a_{i j}(t),
$$

where $A_{i j}(t)$ is the corrected acceleration record and $i$ and $j$ show the subfault position along the rupture length and width, respectively. The correction function $F(t)$ is represented as follows:

$$
\begin{aligned}
F(t)= & \delta(t)+\left[(N-1) / T_{\mathrm{R}}(1-\exp (-1))\right] \\
& \times \exp \left(-t / T_{\mathrm{R}}\right)
\end{aligned}
$$

where $\delta(t)$ denotes the delta function, $N$ represents the total number of subfaults along the rupture length or width and $T_{\mathrm{R}}$ is the rise time of the target earthquake.

However, this technique demands appropriate windowing of the corrected simulated records. In this regard, Kameda and Sugito (1978) suggested the functional form of acceleration envelope $e_{i j}(t)$, which was further modified by Joshi (2004). The multiplication of corrected simulated acceleration recorded with envelope function $e_{i j}(t)$ generates the final acceleration record $a c_{i j}(t)$ as follows:

$$
a c_{i j}(t)=e_{i j}(t) \cdot A_{i j}(t)
$$

and the envelope function $e_{i j}(t)$ is described as follows:

$$
e_{i j}(t)=T_{\mathrm{ss}}\left(t / T_{\mathrm{d}}\right) \cdot \exp \left(1-t / T_{\mathrm{d}}\right),
$$

where $T_{\mathrm{d}}$ and $T_{\mathrm{ss}}$ represent the duration parameter and transmission coefficient, respectively.

The summation of all acceleration records $a c_{i j}(t)$ released from different subfaults in different time periods $t_{i j}$ delivers the final simulated acceleration records $A c(t)$ for target earthquake and is given as follows:

$$
A c(t)=\sum_{i=1}^{N} \sum_{j=1}^{N} a c_{i j}\left(t-t_{i j}\right) .
$$

In recent years, Sandeep et al. (2014a) modified the above technique and successfully used to simulate the strong motion for the 1991 Uttarkashi earthquake in the western part of CSG. In this paper, the same approach has been exploited to simulate strong motion results for the scenario earthquake of magnitude 8.5 in the CSG region.

\section{Data}

In this work, the dataset from three different research papers was used to locate the position of responsible rupture plane and SMGAs within it. The 1991 Uttarkashi earthquake prompted Kayal et al. (1995) to install a temporary microearthquake 
Table 1. Details of three different data sets used in the present study.

\begin{tabular}{|c|c|c|c|c|c|}
\hline Network & Time period & $\begin{array}{l}\text { Total } \\
\text { recorded } \\
\text { events }\end{array}$ & Magnitude & $\begin{array}{l}\text { Depth } \\
\text { range } \\
(\mathrm{km})\end{array}$ & Source \\
\hline $\begin{array}{l}\text { Temporary microearthquake } \\
\text { seismograph network }\end{array}$ & $\begin{array}{l}2 \text { November to } \\
4 \text { December } \\
1991 \text { (33 days) }\end{array}$ & 124 & $2.5-6.8$ & $\leq 26$ & Kayal et al. (1995) \\
\hline USGS seismograph network & $1973-2014$ & 50 & $2.2-5.5$ & $\leq 30$ & $\begin{array}{c}\text { USGS } \\
\text { https://www.usgs.gov/ }\end{array}$ \\
\hline $\begin{array}{l}\text { Strong motion station network } \\
\text { seismicity project MoES, GoI. }\end{array}$ & $2006-2014$ & 110 & $2.5-5.4$ & $\leq 31$ & Kumar et al. $(2015 \mathrm{a}, \mathrm{b})$ \\
\hline
\end{tabular}

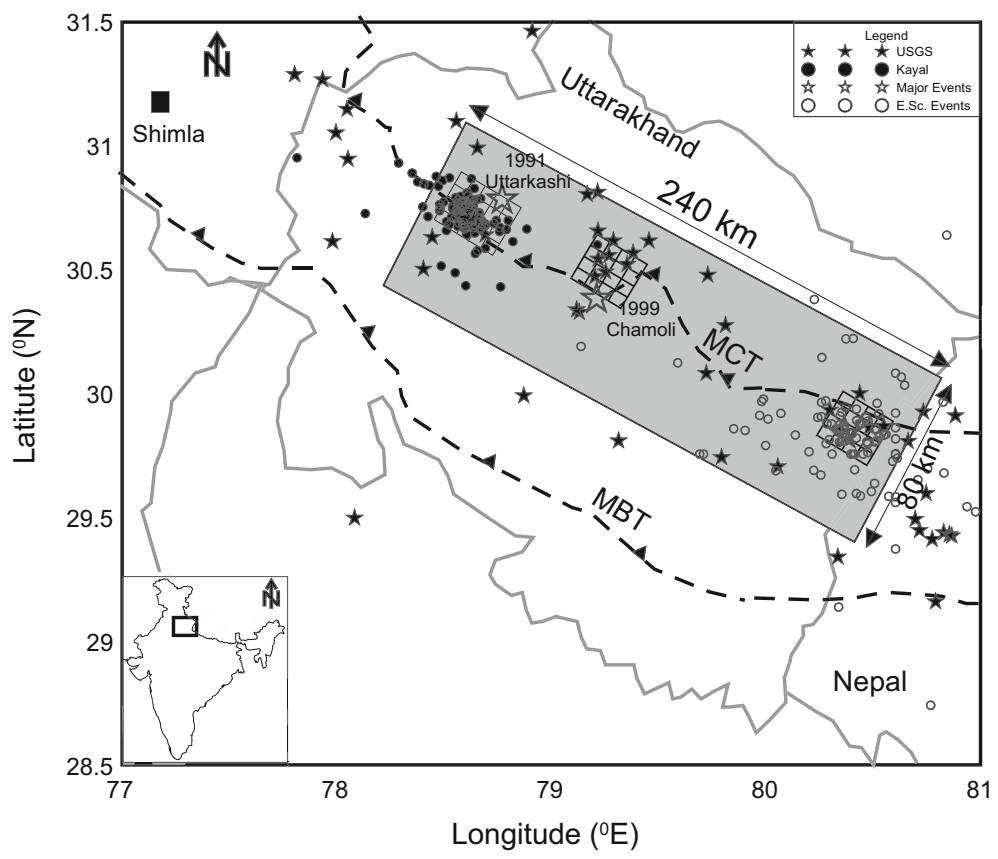

Figure 3. Estimated source model with three SMGAs for the probable great earthquake $\left(M_{\mathrm{w}} 8.5\right)$ in CSG. Solid and hollow circles are the events located by Kayal et al. (1995) and Department of Earth Sciences, Indian Institute of Technology Roorkee, in this region. Solid and hollow stars show the events from USGS and three major events in the region. Dimension of the total rupture area is taken after Yu et al. (1995). (Map after Mukhopadhyay et al. 2011.) MCT, Main Central Thrust; MBT, Main Boundary Thrust; MFT, Main Frontal Thrust.

network in the region. A total of 124 aftershocks were recorded at this microearthquake network and were used for the present study (Kayal et al. 1995).

Under a seismicity project funded by the Ministry of Earth Sciences, Government of India, a network of 14 stations in the highly mountainous terrain of the Kumaon Himalaya was installed. These work stations are maintained by the Department of Earth Sciences, Indian Institute of Technology Roorkee. A total of 110 events were recorded on this network during 2006-2014 and were included in this work. In addition, USGS recorded 50 events in the same region during the period 1973-2014 and were also incorporated in the present study (https://www.usgs.gov/). A brief description and spatial distribution of these events are represented in table 1 and figure 3, respectively.

\section{Rupture model for scenario earthquake in CSG}

$\mathrm{Yu}$ et al. (1995) proposed a rupture plane of dimensions $240 \mathrm{~km} \times 80 \mathrm{~km}$ for a scenario earthquake having a magnitude 8.5 in the CSG region and was used in the present study. However, other 
Table 2. Source parameters of SMGAs identified in the present study.

\begin{tabular}{lcccccc}
\hline SMGAs & $N$ & Strike & Dip & Length $(\mathrm{km})$ & Width $(\mathrm{km})$ & $M_{0}$ dyne $\mathrm{cm}$ \\
\hline References & Kanamori and & Yu et al. $(1995)$ & (suggested & Wells and Coppersmith & CMT Harvard; \\
& Anderson $(1975)$ & for great earthquake) & $(1994)$ & USGS \\
SMGA1 & 5 & $317^{\circ}$ & $6^{\circ}$ & 48 & 36 & $0.8 \times 10^{26}$ \\
SMGA2 & 4 & $317^{\circ}$ & $6^{\circ}$ & 44 & 32 & $7.77 \times 10^{25}$ \\
SMGA3 & 4 & $317^{\circ}$ & $6^{\circ}$ & 45 & 32 & $8.25 \times 10^{25}$ \\
\hline
\end{tabular}

$N$ : number of subfaults.

Table 3. Velocity model (Yu et al. 1995) of the region.

\begin{tabular}{lcc}
\hline $\begin{array}{l}\text { Thickness } \\
(\mathrm{km})\end{array}$ & $\begin{array}{c}V_{\mathrm{s}} \\
(\mathrm{km} / \mathrm{s})\end{array}$ & $\begin{array}{c}\text { Density } \\
\left(\mathrm{kg} / \mathrm{m}^{3}\right)\end{array}$ \\
\hline 0.4 & 2.00 & 1800 \\
1.0 & 2.86 & 2400 \\
15.0 & 2.97 & 2600 \\
30.0 & 3.43 & 2900 \\
\hline
\end{tabular}

research groups including Araya and Kiureghian (1988) and Wells and Coppersmith (1994) estimated $260 \mathrm{~km} \times 80 \mathrm{~km}$ rupture dimensions using different empirical relations. Wyss (1979) postulated the magnitude-rupture area relation that successfully predicted the earthquake of magnitude 8.43 for the above suggested rupture dimensions. The current and past seismicity of the Himalaya region demonstrated that the rupture plane is placed in the north of MBT. Therefore, we utilised a northeast dipping fault at a depth of $18 \mathrm{~km}$ with strike of $317^{\circ}$ and dip of $14^{\circ}$ for this scenario earthquake ( $\mathrm{Yu}$ et al. 1995). Considering the surface offsets along a fault and background seismicity of the region, the high slip rate area on the fault plane can be determined (Irikura and Miyake 2011). In (a)

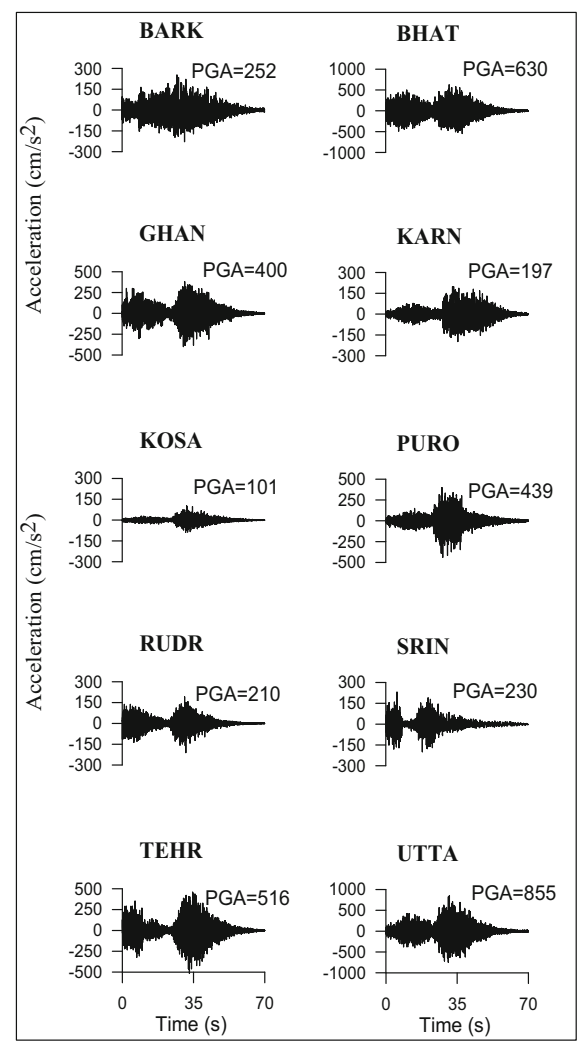

(b)

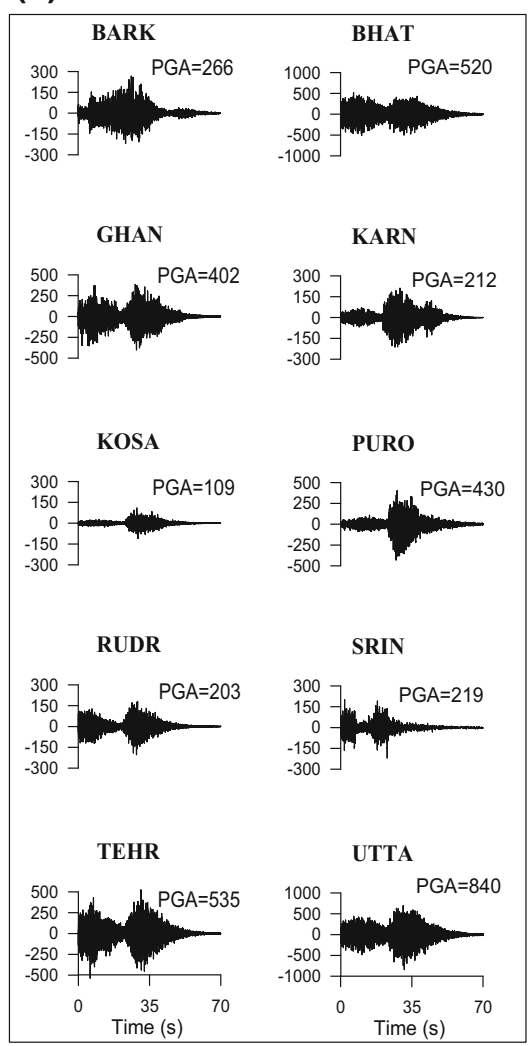

(c)

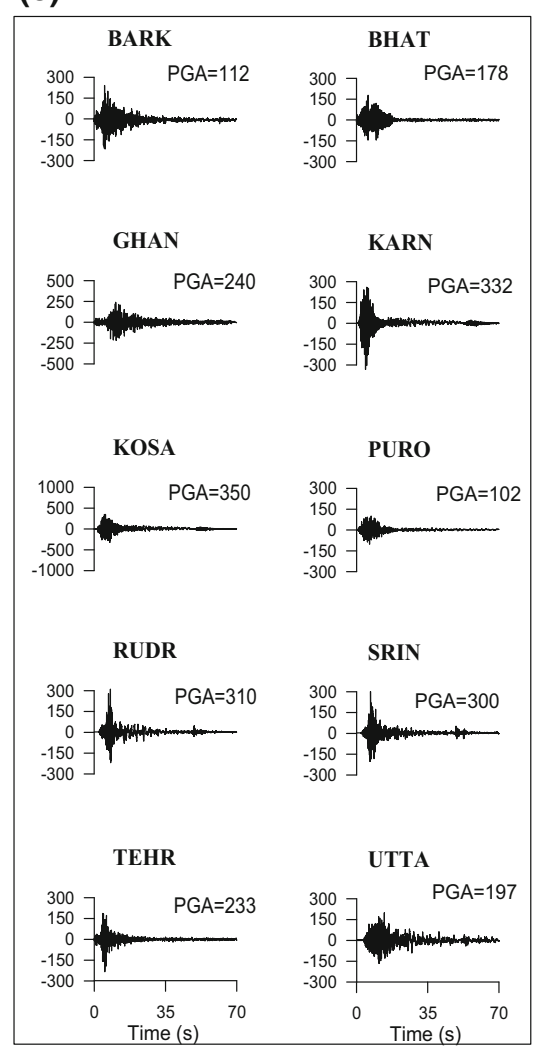

Figure 4. Simulated acceleration records for the probable great earthquake $\left(M_{\mathrm{w}} 8.5\right)$ at BARK, GHAN, KOSA, RUDR, TEHR, BHAT, KARN, PURO, SRIN and UTTA stations assuming the epicentre of the probable great earthquake as the location of nucleation point of: (a) SMGA1, (b) SMGA2 and (c) SMGA3. 
the present study, three SMGAs were identified based on three different clusters of 284 earthquake events in the Himalaya region (figure 3). Each cluster serves as different source of energy and possible location of SMGAs in the rupture plane. These are modelled as SMGAs and termed as SMGA1, SMGA2 and SMGA3. During a future great earthquake, the actual location of SMGAs may alter, which directly influences the acceleration results. However, dense GPS network may provide better slip rates and absolute locations of SMGAs. On the basis of self-similarity relations (Kanamori and Anderson 1975), the rupture plane of SMGA1, SMGA2 and SMGA3 was partitioned into $5 \times 5,4 \times 4$ and $4 \times 4$ grids, respectively, as shown in figure 3 and table 2. Event of $M_{\mathrm{w}} 5.4$ was used as a subfault for rupture division of SMGA1 and SMGA2, whereas $M_{\mathrm{w}} 5.2$ was utilised for SMGA3. The selection of the events was carefully done as these have similar faulting mechanism and focal depth as that of the target earthquake.

The seismicity of the study area described that the epicentres of Uttarkashi and Chamoli earthquakes are situated in SMGA1 and SMGA2, respectively. On the basis of this study, these events (i.e., rupture planes and seismic moments) are considered as SMGA1 and SMGA2. On the other hand, SMGA3 is located in the Kumaon region along the boundary of India and Nepal. Therefore, the 1980 Nepal earthquake $\left(M_{\mathrm{w}} 6.5\right)$ in the eastern Kumaon region is considered as SMGA3. The USGS and Global Centroid-Moment-Tensor (CMT) provided the fault plane mechanism for 1991 Uttarkashi $\left(\phi=296^{\circ}, \delta=5^{\circ}\right.$ and $\left.\lambda=90^{\circ}\right), 1999$ Chamoli $\left(\phi=282^{\circ}, \delta=9^{\circ}\right.$ and $\left.\lambda=95^{\circ}\right)$ and 1980 Nepal China earthquake $\left(\phi=290^{\circ}, \delta=21^{\circ}\right.$ and $\lambda=91^{\circ}$ ), which have been used for SMGAs. The high dip $\left(21^{\circ}\right)$ for the 1980 Nepal earthquake than the Uttarkashi $\left(\sim 5^{\circ}\right)$ and Chamoli $\left(\sim 9^{\circ}\right)$ earthquakes suggests that the Main Himalayan Thrust (MHT) is much steeper in the Kumaon region than in the Garhwal region. In addition, Kumar et al. (2015b) reported two different attenuation relations $96 \mathrm{f}^{1.06}$ and $65 \mathrm{f}^{1.07}$ for Garhwal and Kumaon regions, respectively, which have been considered for the strong motion study in this work. These two aforementioned factors, i.e., steeper dip of fault plane and different attenuation characteristics of the Kumaon region explain the different distribution pattern of predicted PGA values in the case of SMGA3.

$\mathrm{Yu}$ et al. (1995) derived a velocity model for this region as described in table 3 . The rupture plane

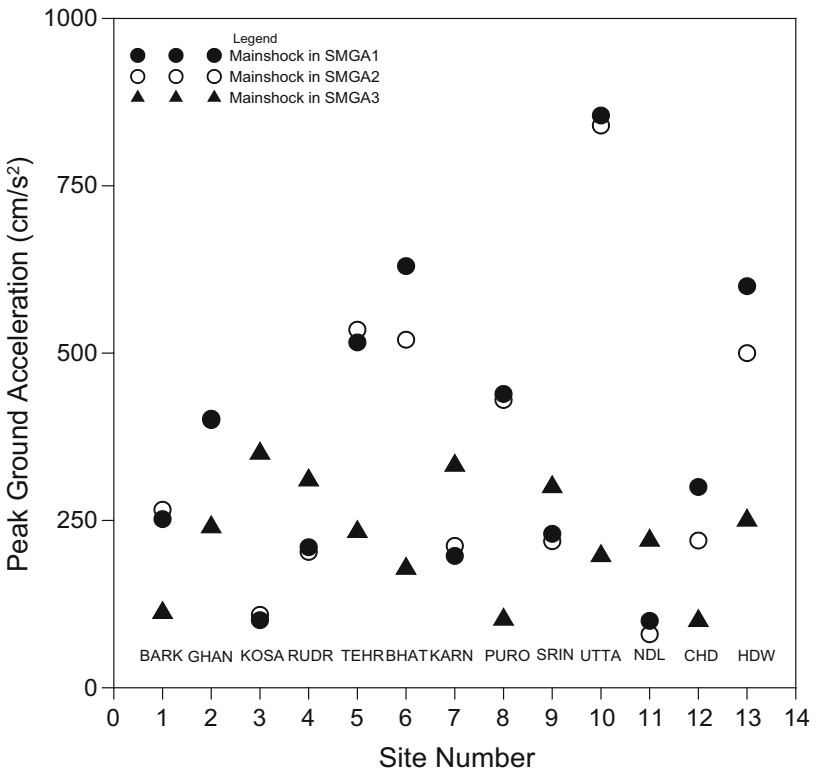

Figure 5. Variation of simulated PGA at every site for three different possible locations of mainshock.

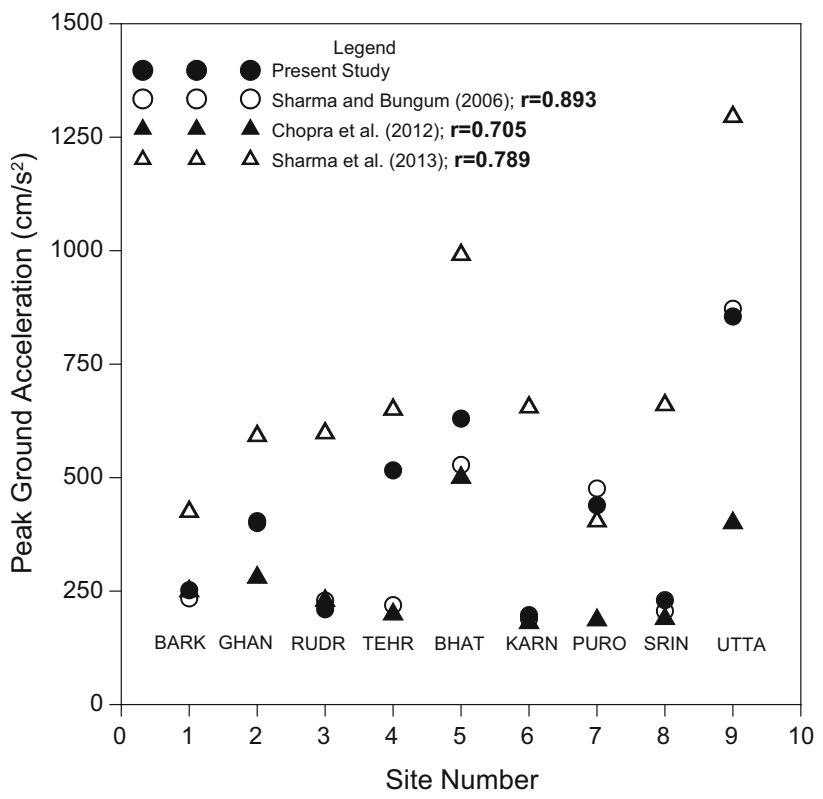

Figure 6. Comparison of simulated PGA values in the present study with other studies in the region. ' $r$ ' represents the correlation coefficient values between simulated PGA and other three studies in the region.

was situated at a depth of $18 \mathrm{~km}$ in the fourth layer of this velocity model.

\section{Results and discussion}

In the present work, the entire study area (extending between latitude $76-83^{\circ} \mathrm{E}$ and longitude $28-32^{\circ} \mathrm{N}$ ) was divided into $0.5^{\circ} \times 0.5^{\circ}$ square grids. MSET was used to simulate the horizontal 
Table 4. PGA values at different locations for three different locations of mainshock in rupture plane.

\begin{tabular}{|c|c|c|c|c|c|}
\hline Station & $\begin{array}{l}\text { Station } \\
\text { code }\end{array}$ & $\begin{array}{c}\text { PGA (gal) } \\
\text { mainshock } \\
\text { location in } \\
\text { SMGA1 }\end{array}$ & $\begin{array}{l}\text { PGA (gal) } \\
\text { mainshock } \\
\text { location in } \\
\text { SMGA2 }\end{array}$ & $\begin{array}{c}\text { PGA (gal) } \\
\text { mainshock } \\
\text { location in } \\
\text { SMGA3 }\end{array}$ & $\begin{array}{c}\text { Geology of the region } \\
\text { (Sharma et al. 2013) }\end{array}$ \\
\hline Barkot & BARK & 252 & 266 & 112 & Quartzite and phyllites \\
\hline Ghansali & GHAN & 400 & 402 & 240 & Quartzite and phyllites \\
\hline Kosani & KOSA & 101 & 109 & 350 & $\begin{array}{l}\text { Quartzite, schist } \\
\text { and granite }\end{array}$ \\
\hline Rudra Prayag & RUDR & 210 & 203 & 310 & $\begin{array}{l}\text { Quartzite, schist } \\
\text { and granite }\end{array}$ \\
\hline Tehri & TEHR & 516 & 535 & 273 & $\begin{array}{l}\text { Quartzitic phyllite and } \\
\text { schistose phyllite }\end{array}$ \\
\hline Bhatwari & BHAT & 630 & 520 & 178 & $\begin{array}{l}\text { Quartzites, schists } \\
\text { and gneisses }\end{array}$ \\
\hline Karan Prayag & KARN & 197 & 212 & 332 & $\begin{array}{c}\text { Quartzitic phyllites and } \\
\text { massive quartzites }\end{array}$ \\
\hline Purola & PURO & 439 & 430 & 102 & Quartzite and phyllites \\
\hline Sri Nagar & SRIN & 230 & 219 & 300 & Quartzite \\
\hline Uttarkashi & UTTA & 855 & 840 & 197 & Quartzite and phyllites \\
\hline New Delhi & NDL & 100 & 80 & 220 & Alluvium \\
\hline Chandigarh & CHD & 300 & 220 & 100 & Alluvium \\
\hline Haridwar & HDW & 600 & 500 & 250 & Alluvium \\
\hline
\end{tabular}

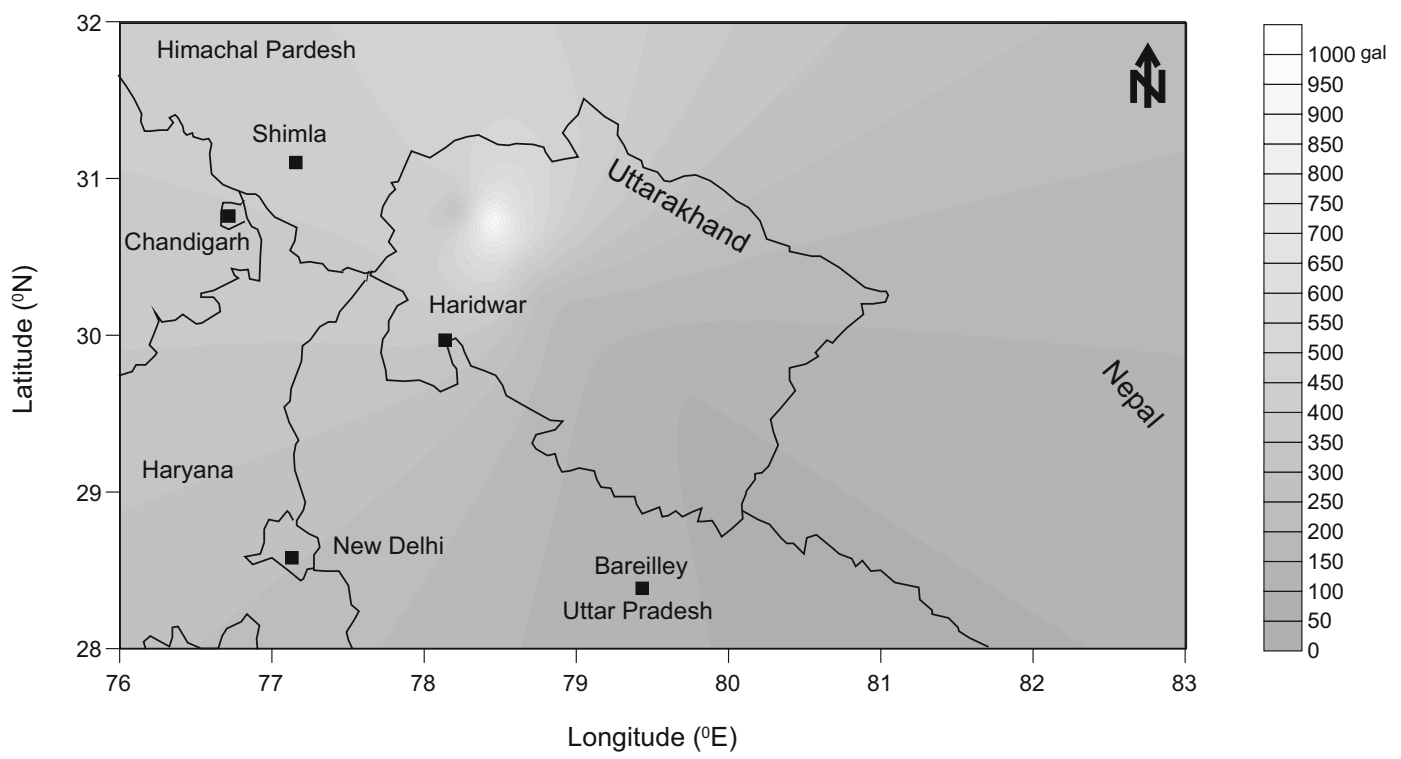

Figure 7. Isoacceleration map of the region assuming the location of the probable earthquake in SMGA1 close to the mainshock of the 1991 earthquake in the Uttarkashi region.

component of strong motion records at every corner of the grid. Figure 4 shows the simulated records at 10 real recording sites. In the source model, SMGAs led to the peculiar shapes at different stations (SRIN, TEHR and UTTA). As a consequence, three different cases correspond to three different possible locations of nucleation point of the probable earthquake (8.5) were assumed. The epicentre of the probable earthquake was considered as the nucleation point of SMGA1, SMGA2 and SMGA3 (the extreme northeast of every SMGA). The variation of simulated PGA at every site for three different locations of mainshock is described in figure 5 and table 4 .

Moreover, the simulated PGA values are compared with earlier studies for the same region using 

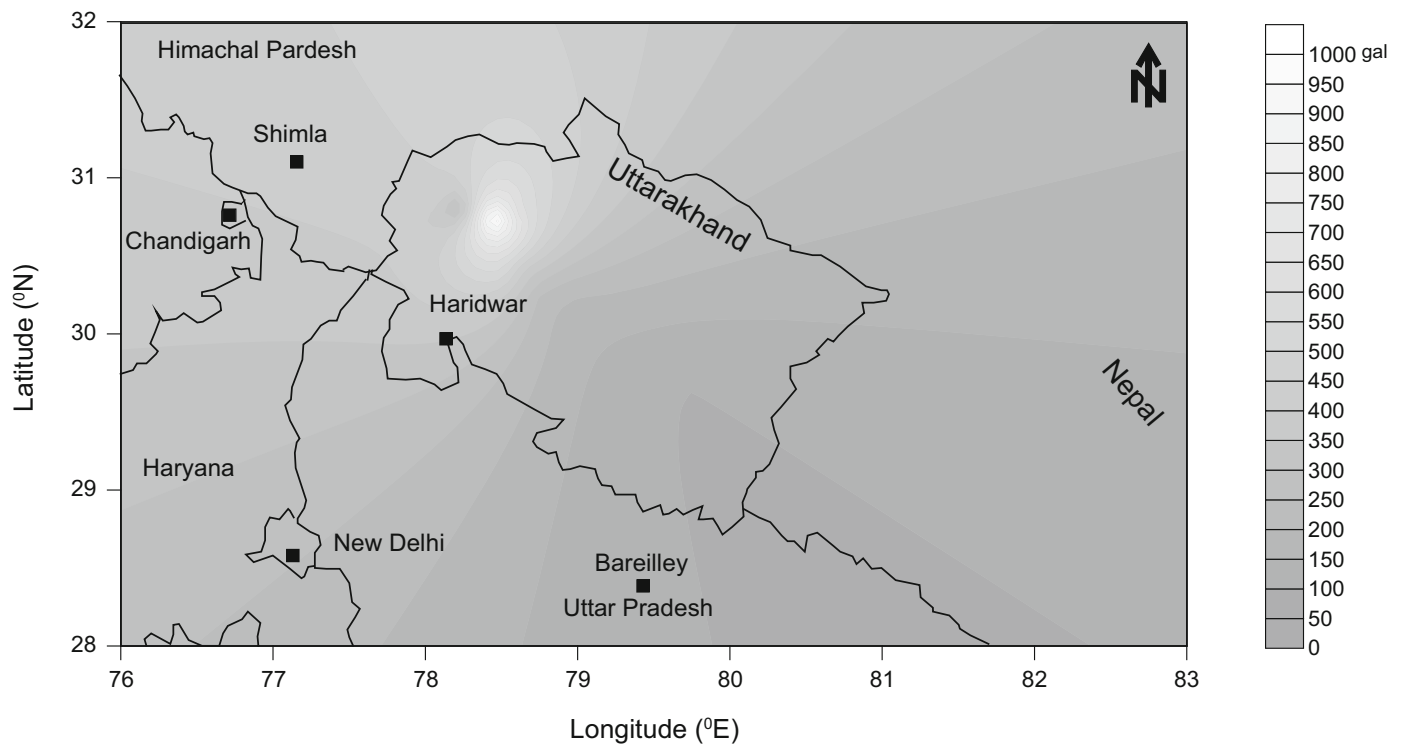

Figure 8. Isoacceleration map of the region assuming the location of the probable earthquake in SMGA2 close to the mainshock of the 1999 earthquake in the Chamoli region.
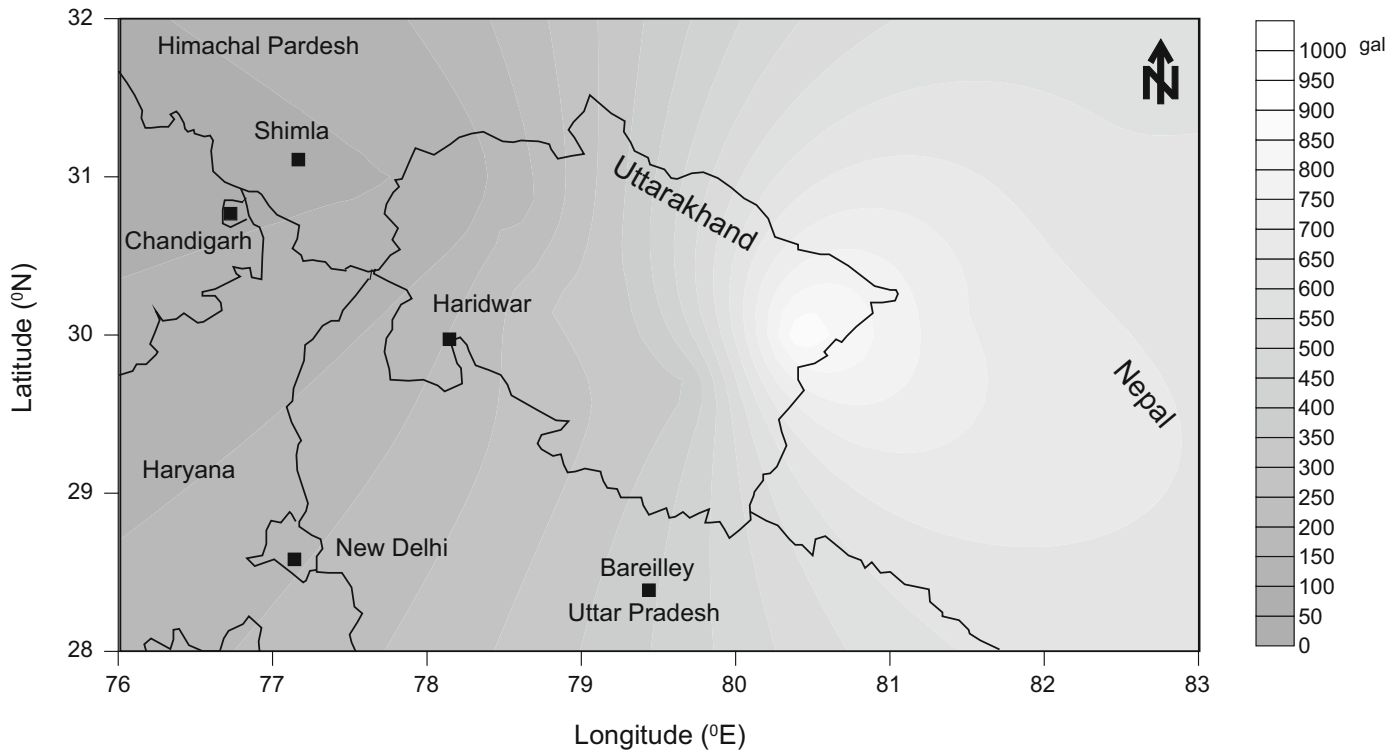

Figure 9. Isoacceleration map of the region assuming the location of the probable earthquake in SMGA3.

the correlation coefficient $(r)$ as shown in figure 6 . (Chopra et al. 2012; Sharma et al. 2013; Sharma and Bungum 2006). Isoacceleration maps for all the three possible locations of mainshock have been developed using simulated records at every corner of the grid (figures 7-9).

\section{Conclusions and future scope}

In conclusion, a source model with three SMGAs for a future probable earthquake $\left(M_{\mathrm{w}} 8.5\right)$ in the
CSG region has been estimated. An attempt is made to evaluate the PGA distribution in the region using MSET. It is observed that PGA values are comparable for the assumed epicentre of probable earthquake in SMGA1 and SMGA2. The highest PGA is estimated at Uttarkashi station, whereas the lowest is obtained at Kosani. However, Kosani would experience the highest PGA for mainshock location in SMGA3, whereas Purola site would observe the lowest. Haridwar, Chandigarh and New Delhi would observe PGA values of 600,300 and 100 gal, respectively, for the 
mainshock location in SMGA1 and 500, 220 and 80 gal, respectively, for the mainshock in SMGA2. From the above analysis, we concluded that PGA would be higher in Haridwar and Chandigarh than New Delhi city for SMGA1 and SMGA2. In contrast, New Delhi would observe a higher PGA value than Chandigarh for nucleation point located in SMGA3. The variation in PGA values with mainshock location can be attributed to the directivity effects of the rupture propagation. Furthermore, the simulated PGA values in the present work are more or less comparable with previous studies in the same region.

\section{Acknowledgements}

The authors are grateful to Dr Preeti for her valuable efforts to improve the quality of the paper. The authors sincerely acknowledge the editorial board and two anonymous reviewers for their critical review and constructive suggestions. The authors sincerely thank Kayal et al. (1995), USGS (https://www.usgs.gov/), CMT Harvard (http:// www.globalcmt.org/), Ministry of Earth Sciences (project reference no. MoES/P.O.(Seismo)/1(42) /2009) for using earthquake data. This work is an outcome of project reference no. ECR/2016/000737 supported by the Science and Engineering Research Board, DST, India. We gratefully acknowledge the Department of Geophysics, Banaras Hindu University, Varanasi and Department of Earth Sciences, Indian Institute of Technology, Roorkee, for providing basic facilities for this research work. The author AS is highly thankful to Prof N P Singh for his valuable suggestions to improve the quality of research work. The author PK sincerely acknowledges the Director, Wadia Institute of Himalayan Geology, Dehradun.

\section{References}

Aki K 1967 Scaling law of seismic spectrum; J. Geophys. Res. 72 1217-1231.

Araya R and Kiureghian A D 1988 Seismic hazard analysis, improved models, uncertainties and sensitivities; Report No. EERC-90/11, Earthquake Engineering Research Center, University of California, Berkeley, CA, 155p.

Asano K and Iwata T 2012 Source model for strong ground motion generation in the frequency range $0.1-$ $10 \mathrm{~Hz}$ during the 2011 Tohoku earthquake; Earth Planet. Space 64(12) 1111-1123.
Bhatia S C, Kumar M R and Gupta H K 1999 A probabilistic seismic hazard map of India and adjoining regions; Annalidi Geofisica 42 1153-1164.

Boore D M 1983 Stochastic simulation of high frequency ground motion based on seismological models of radiated Spectra; Bull. Seismol. Soc. Am. 73 1865-1894.

Bilham R 1995 Location and magnitude of the Nepal earthquake and its relation to the rupture zones of the contiguous great Himalayan earthquakes; Curr. Sci. 69 101-128.

Bilham R, Gaur V K and Molnar P 2001 Himalayan seismic hazard; Science 293 1442-1444.

Brune J N 1970 Tectonic stress and spectra of seismic shear waves from earthquakes; J. Geophys. Res. 75 4997-5009.

Chopra S, Kumar V, Suthar A and Kumar P 2012 Modeling of strong ground motions for 1991 Uttarkashi, 1999 Chamoli earthquakes, and a hypothetical great earthquake in Garhwal-Kumaun Himalaya; Nat. Hazards 64 1141-1159.

Irikura K and Kamae K 1994 Estimation of strong ground motion in broad-frequency band based on a seismic source scaling model and an Empirical Green's function technique; Ann. Geofis. XXXVII 6 1721-1743.

Irikura K and Miyake H 2011 Recipe for predicting strong ground motion from crustal earthquake scenarios; Pure Appl. Geophys. 168(1-2) 85-104.

Irikura K, Kagawa T and Sekiguchi H 1997 Revision of the empirical Green's function method by Irikura, 1986, programme and abstracts; Zisin 2 B25.

IS:1893 2002 Indian standard criteria for earthquake resistant design of structures; Bureau of Indian Standards, New Delhi.

Joshi A 2001 Strong motion modeling of the source of the Chamoli earthquake of March 29, 1999 in the Garhwal Himalaya, India; J. Seismol. 5 499-518.

Joshi A 2004 A simplified technique for simulating wide band strong ground motion for two recent Himalaya earthquakes; Pure Appl. Geophys. 161 1777-1805.

Joshi A and Midorikawa S 2004 A simplified method for simulation of strong ground motion using rupture model of the earthquake source; J. Seismol. 8 467-484.

Joshi A and Mohan K 2010 Expected peak ground acceleration in Uttarakhand Himalaya, India region from a deterministic hazard model; Nat. Hazards 52 299-317.

Joshi A and Patel R C 1997 Modelling of active lineaments for predicting a possible earthquake scenario around Dehradun, Garhwal Himalaya, India; Tectonophys. 283 289-310.

Joshi A, Sandeep A and Kamal 2014 Modeling of strong motion generation areas of the 2011 Tohoku, Japan earthquake using modified semi-empirical technique; Nat. Hazards 71 587-609.

Joshi A, Kumar B, Sinvhal A and Sinvhal H 1999 Generation of synthetic accelerograms by modeling of rupture plane; J. Earthq. Tech. 36 43-60.

Joshi A, Singh S and Giroti K 2001 The simulation of ground motions using envelope summations; Pure Appl. Geophys. 158 877-901.

Joshi A, Kumari P, Sharma M L, Ghosh A K, Agarwal M K and Ravikiran A 2012a A strong motion model of the 2004 great Sumatra earthquake: Simulation using a modified semi-empirical method; J. Earthq. Tsunami 6 1-29. 
Joshi A, Kumari P, Singh S and Sharma M L 2012b Nearfield and far-field simulation of accelerograms of Sikkim earthquake of September 18, 2011 using modified semiempirical approach; Nat. Hazards 64 1029-1054.

Joshi A, Kuo C H, Dhibar P, Sandeep A, Sharma M L, Wen K L and Lin C M 2015 Simulation of the records of the 27th March 2013, Nantou Taiwan earthquake using modified semi-empirical approach; Nat. Hazards 78 995-1020.

Kamae K and Kawabe H 2004 Source model composed of asperities for the 2003 Tokachi-oki, Japan, earthquake (M JMA $=8.0)$ estimated by the empirical Green's function method; Earth Planets Space 56(3) 323-327.

Kameda H and Sugito M 1978 Prediction of strong earthquake motions by evolutionary process model; In: Proceedings of the sixth Japan earthquake engineering symposium, pp. 41-48.

Kanamori H and Anderson D L 1975 Theoretical basis of some empirical relations in seismology; Bull. Seismol. Soc. Am. 65 1073-1095.

Kayal J 2014 Seismotectonics of the great and large earthquakes in Himalaya; Curr. Sci. 106(2) 188-197.

Kayal J R, Ghosh B, Chakraborty P and Reena D 1995 Aftershock study of Uttarkashi earthquake of October 20, 1991 by a temporary micro earthquake network; Memoir Geol. Soc. India 30 25-41.

Khattri K N 1987 Great earthquakes seismicity gaps and potential for earthquake disaster along the Himalaya plate boundary; Tectonophys. 138 79-92.

Khattri K N 1999 An evaluation of earthquakes hazard and risk in northern India; Him. Geol. 20 1-46.

Khattri K N and Tyagi A K 1983 Seismicity patterns in the Himalayan plate boundary and identification of areas of high seismic potential; Tectonophys. 96 281-297.

Kumar D, Teotia S S and Khattari K N 1997 The representation of attenuation characteristics of strong ground motion observed in the 1996 Dharamshala and 1991 Uttarkasshi earthquakes by available Empirical relations; Curr. Sci. 73 543-548.

Kumar P, Joshi A, Sandeep, Ashvini K and Chadha R K 2015a Detailed attenuation characteristics of shear waves in Kumaon Himalaya, India using the inversion of strong motion data; Bull. Seismol. Soc. Am. 105 1836-1851.

Kumar A, Sinvhal A, Joshi A, Kumar D, Sandeep and Kumar P 2015b Coda wave attenuation characteristics for Kumaon and Garhwal Himalaya, India; Nat. Hazards 75 1057-1074.

Kurahashi S and Irikura K 2011 Source model for generating strong ground motion during the 2011 off the Pacific coast of Tohoku earthquake; Earth Planet. Space 63 571-576.

Midorikawa S 1993 Semi empirical estimation of peak ground acceleration from large earthquakes; Tectonophys. 218 287-295.

Miyake H, Iwata T and Irikura K 1999 Strong ground motion simulation and source modeling of the Kagoshima-ken Hokuseibu earthquakes of March 26 (MJMA 6.5) and May 13 (MJMA 6.3), 1997, using empirical Green's function method; Zisin 51 431-442 (in Japanese with English abstract).

Miyake H, Iwate T and Irikura K 2001 Estimation of rupture propagation direction and strong motion generation area from azimuth and distance dependence of source amplitude spectra; Geophys. Res. Lett. 28 2727-2730.
Miyake H, Iwate T and Irikura K 2003 Source characterization for broadband ground-motion simulation: Kinematic heterogeneous source model and strong motion generation area; Bull. Seismol. Soc. Am. 93 2531-2545.

Miyahara M and Sasatani T 2004 Estimation of source process of the 1994 SanrikuHaruka-oki earthquake using empirical Green's function method; Geophys. Bull. Hokkaido Univ. Sapporo. Japan 67 197-212.

Mukhopadhyay B, Acharyya A and Dasgupta S 2011 Potential source zones for Himalayan earthquakes: Constraints from spatial-temporal clusters; Nat. Hazards $\mathbf{5 7}$ 369-383.

Nath S K, Shukla K and Vyas M 2008 Seismic hazard scenario and attenuation model of the Garhwal Himalaya using near-field synthesis from weak motion seismometry; J. Earth Syst. Sci. 117 649-670.

Ni J and Barazangi M 1984 Seismotectonics of the Himalayan collision zone: Geometry of the under thrusting Indian plate beneath the Himalaya; J. Geophys. Res. 89 1147-1163.

Sandeep, Joshi A, Kamal, Kumar P and Kumar A 2014a Effect of frequency dependent radiation pattern in simulation of high frequency ground motion of Tohoku earthquake using modified semi empirical method; Nat. Hazards 73 1499-1521.

Sandeep, Joshi A, Kamal, Kumar $\mathrm{P}$ and Kumari $\mathrm{P}$ 2014b Modeling of strong motion generation area of the Uttarkashi earthquake using modified semi-empirical approach; Nat. Hazards 73 2041-2066.

Sandeep, Joshi A, Kamal, Kumar P, Kumar A and Dhibar P 2015 Modeling of strong motiongeneration areas of the Niigata, Japan, earthquake of 2007 using modified semi empiricaltechnique; Nat. Hazards 77 933957.

Sandeep A, Joshi A, Kumari P, Lal S, Vandana, Kumar P and Kamal 2017a Emergence of the semi-empirical technique of strong ground motion simulation: A review; $J$. Geol. Soc. India 89 719-722.

Sandeep, Joshi A, Sah S K, Kumar P, Lal S, Vandana, Kamal and Singh R S 2017b Source model estimation of the 2005 Kyushu earthquake, Japan using modified semi empirical technique; J. Asian Earth Sci. 147 240-253.

Sandeep, Joshi A, Lal S, Kumar P, Sah S K, Vandana and Kamal 2017c Simulation of strong ground motion of the 2009 Bhutan earthquake using Modified Semi Empirical Technique. Pure Appl. Geophys. 174 4343-4356.

Seeber L, Armbruster J G and Quittmeyer R C 1981 Seismicity and continental subduction in Himalayan arc. In: Hindu Kush, Himalaya: Geodynamic evolution Geodyn. Ser. 3 (eds) Gupta H K and Delany F M, Am. Geophys. Union, Washington, DC, pp. 215-242.

Sharma M L and Bungum H 2006, New strong groundmotion spectral acceleration relations for the Himalayan region; In: Proceedings, first European conference on earthquake engineering and seismology (ECEES), Paper 1312,8 .

Sharma B, Chopra S, Sutar A K and Bansal B K 2013 Estimation of strong ground motion from a great earthquake mw 8.5 in central seismic gap region, Himalaya (India) using empirical Green's function technique; Pure Appl. Geophys. 170 2127-2138. 
Srivastava H N, Verma M, Bansal B K and Sutar A K 2015 Discriminatory characteristics of seismic gaps in Himalaya; Geomatics, Nat. Hazards Risk 6(3) $224-242$.

Suzuki W and Iwata T 2007 Source model of the 2005 Miyagi-Oki, Japan, earthquake estimated from broadband strong motions; Earth Planet. Space 59(11) $1155-1171$.

Takiguchi M, Asano K and Iwata T 2011 The comparison of source models of repeating subduction-zone earthquakes estimated using broadband strong motion records1982 and 2008 Ibaraki-ken-oki M7 earthquakes; Zisin 63 $223-242$

Corresponding editor: ARKOPROvO BISWAS
Wells L D and Coppersmith K J 1994 New empirical relationships among magnitude, rupture length, rupture width, rupture area and surface displacement; Bull. Seismol. Soc. Am. 84 974-1002.

Wyss M 1979 Estimating maximum expectable magnitude of earthquakes from fault dimensions; Geol. Soc. Am. 7(7) 336-340.

Yu G, Khattri K N, Anderson J G, Brune J N and Zeng Y 1995 Strong ground motion from the Uttarkashi, Himalaya, India, earthquake: Comparison of observations with synthetics using the composite source model; Bull. Seismol. Soc. Am. 85 31-50. 